\title{
Sobre Determinado Uso do Enquadre na Pesquisa Qualitativa em Saúde: a Questão do Analisador Natural
}

| Manola Vidal |

Resumo: Este artigo procura demonstrar a inclusão, nos limites do enquadre metodológico da pesquisa qualitativa em saúde, de um analisador natural surgido na dinâmica da relação entre pesquisador e sujeito da pesquisa. A investigação sobre o humor materno em mães de bebês prematuros após a alta hospitalar, objeto de pesquisa de doutoramento em Saúde da Mulher, apresentou uma interface com as reaçôes emocionais experienciadas no interior do ambiente de tratamento intensivo. A análise e interpretação do material da pesquisa referente a esse período contribuíram de forma a reparar a condição de vulnerabilidade moral de um grupo frequentemente excluído do conhecimento sobre os processos de humanização de assistência à saúde, o das mães em alojamento conjunto na internação de seus filhos, contribuindo para reflexôes sobre a ética em pesquisa com seres humanos.

Palavras-chave: ética; analisador natural; pesquisa qualitativa.
${ }^{1}$ Psicóloga; psicanalista; mestre em Saúde da Criança (FiocruzInstituto Fernandes Figueira); doutora em Saúde da Mulher (Fiocruz-Instituto Fernandes Figueira) e pós-doutoranda em Psicanálise e Saúde Mental (UFRJ-Instituto de Psiquiatria). Endereço eletrônico: manolavidal@terra.com.br 


\section{Introdução}

O objetivo aqui pretendido é demonstrar a integração, nos limites do enquadre metodológico de pesquisa qualitativa em saúde, do surgimento de um analisador natural na dinâmica da relação entre pesquisador e sujeito da pesquisa. Trata-se de um recorte realizado em tese de doutorado (VIDAL, 2006) em Saúde da Mulher cujo objeto de estudos foi o humor materno em mães de bebês prematuros após a alta hospitalar.

A metodologia da pesquisa qualitativa orienta-se pela utilização de técnicas que se propõem a captar com profundidade os significados de motivações, aspirações, crenças e valores, da interação entre o sujeito e seu mundo (MINAYO, 1993 e 2006). Esta apreensão se dá através da observação, análise e interpretação do que se expressa através da linguagem na vida cotidiana. Quando aplicada à pesquisa sobre os processos relativos à saúde e à doença, os estudos de pessoas e determinados grupos historicamente situados demonstram a articulação dos discursos médicos com outras forças e campos sociais. Suas técnicas se referem ao uso de múltiplas fontes (documentária e oral) no processo de reconstituição das diferentes lógicas que presidem os modelos etiológicos e terapêuticos da prática médica na sociedade contemporânea.

O conceito de analisador se origina da socioanálise ${ }^{1}$, através das contribuições de Guattari (1987) e está relacionado às intervençôes em psicoterapia institucional e à especificidade que podemos encontrar na definição de instituição pela socioanálise.

O conhecimento produzido a partir da Segunda Grande Guerra no campo da saúde mental foi orientado pela reforma na assistência hospitalar até então centrada no modelo de hospício. Dentre os movimentos ${ }^{2}$ que criticavam tal modelo está o da psicoterapia institucional, que possui sua origem na França a partir da liderança de François Tosquelles no hospital de Saint Alban. Com forte influência da psicanálise e do pensamento marxista, a psicoterapia institucional buscava tratar das próprias características doentias das instituições. Já a definição de instituição para a socioanálise se refere às formas de relaçôes sociais produzidas, reproduzidas, transformadas e/ou invertidas que são instrumentalizadas a partir de um processo de institucionalização. Os processos de institucionalização dos modos de relaçôes sociais tendem a ocultar sua determinação pela história, produzindo o efeito de "naturalizar", por meio da repetição, as práticas institucionais. 
A produção de um analisador, por esse processo que naturaliza o que é historicamente determinado, encontra-se na irrupção da fala dos indivíduos na medida em que esta adentra a instituição. A fala possui valor terapêutico e político, na medida em que está subjugada pela verticalidade (organograma de uma estrutura piramidal) e horizontalidade (uma fala entre os "iguais"), contida nos modos de relação social instituídos. É a via principal pela qual se conhece a realidade da instituição.

Se foi através da psicoterapia institucional, atrelada às situações de intervenção, que analisadores artificiais ${ }^{3}$ eram construídos para provocar a fala "libertadora", na situação da pesquisa aqui apresentada este elemento foi atípico, inesperado, um acaso, não estando sob controle prévio. Sua iluminação pode revelar as implicações contidas em relação a minha posição de observadora, diante desta história de vida.

Tais implicações se aproximam do que a socioanálise apresenta como sendo a posição do analista, do interveniente, em relação à ideologia da instituiçãa. Como ideologia, conforme definido por Chauí (2002), entende-se a tentativa de fazer com que o ponto de vista particular da classe, neste caso da instituição que exerce a dominação política, apareça a todos os sujeitos sociais como naturalizado, e não como interesse particular de determinada classe ou grupo. Na situação aqui apresentada, a inclusão da fala "libertadora" na instituição se deu a partir do trabalho de elaboração teórica realizado na construção de tese de doutorado, a partir da compreensão de que o surgimento do analisador realizava uma "encomenda" ${ }^{4} \mathrm{e}$ que esta era dirigida aos processos de humanização da assistência. A interpretação do material colhido contido no texto da tese revelou, portanto minha implicação, ou seja, minha posição em relação à ideologia da instituição, através da avaliação sobre a importância de se expor determinados aspectos, já instituídos nos modos de relação social, presentes na comunicação médico-paciente.

\section{A dinâmica da relação entre pesquisador e sujeito da pesquisa}

O enquadre metodológico da pesquisa qualitativa em saúde possibilitou investigar o significado atribuído por quatro mães ao acompanhamento da internação hospitalar eà interação com seus bebês em ambiente doméstico. Foram construídas suas histórias de vida, focalizando o período relativo ao projeto da maternidade, após parto prematuro, considerando-se a unidade temporal relativa ao acompanhamento da 
internação na unidade de tratamento intensivo e os seis primeiros meses após a alta hospitalar. Realizou-se uma abordagem tópica, mas que permitiu contemplar o passado, interpretar o presente e realizar projeçōes no futuro através do significado que as mães atribuíram à experiência de humor deprimido durante a internação e após a alta hospitalar de seus filhos. Foram utilizadas entrevistas não-diretivas, abertas, e observação participante, que possibilitaram o desenvolvimento de uma escuta apurada e uma atitude reflexiva. Este trabalho se refere ao período do acompanhamento materno da internação em unidade de atendimento intensivo realizado por uma das quatro mães selecionadas para a pesquisa.

Conheci Wanda ${ }^{5}$ no interior da Unidade de Atendimento Intensivo em Neonatologia do Instituto Fernandes Figueira, onde realizei a primeira fase do trabalho de campo da pesquisa. Acompanhei-a durante o período de internação hospitalar de sua filha, três meses e quatro dias, e por seis meses após a alta, através de visitas domiciliares mensais. Freqüentemente, em nossos encontros no interior do ambiente de atendimento intensivo, ela descrevia suas reações emocionais diante do "esclarecimento" fornecido, pela equipe de saúde da instituição, sobre os riscos que a acompanhavam desde a gestação de sua filha. Compreendi que essa freqüência estava ligada a uma determinada forma de utilização do enquadre da pesquisa e que correspondia ao efeito produzido por um analisador, ou seja, o de determinado tipo de comunicação através da qual o indivíduo interpreta a instituição. Esta observação, a da existência de um analisador "natural" que se apresentava através de sua fala durante nossos encontros, me conduziu à compreensão de que sua interpretação se dirigia a determinados aspectos do processo de humanização da assistência à gravidez, parto e puerpério em situações de risco especialmente referidos à forma como as comunicações sobre os estados clínicos, seu e de sua filha, lhes eram dirigidas.

[...] E na hora lá no hospital eu internada por causa da gravidez, o médico veio e disse que talvez nem eu sobrevivesse, (chora) se era para eu morrer lá, e eu me perguntava se era para eu morrer, tentava aceitar isso (chora) os médicos falavam que eu estava tão ruim [...]. Eu sabia que podia morrer na operação, que era mais do que possível, então eu falava com Deus eu aceitava também, se fosse para eu morrer, que eu morresse se ele achava que seria o melhor para mim [...].

[...] Sabe aquele dia em que cheguei aqui e ela não estava, tinha ido lá para o outro lado, e quando cheguei levei o maior susto, achando que ela tinha morrido. Comecei a passar mal, gritar (transferiram o bebê da unidade de atendimento 


\begin{abstract}
intensivo para uma unidade intermediária por $24 \mathrm{hs}$, sem aviso prévio à mãe, que neste período não estava em alojamento conjunto, em função da lotação da unidade) aí veio uma profissional aqui, sei lá quem ela era, veio para falar que hospital público era assim e falou: "Você sabe por que sua filha sobreviveu?". Aí ela mesma respondeu: "Ela sobreviveu porque está aqui." Não estou conseguindo falar o que sinto, eu disse meio nervosa. Não é bem assim, porque se fosse quando ela nasceu o meu marido não tinha que assinar um termo de responsabilidade, o médico durante a minha gravidez tinha me falado que era para eu não ter esperança. Eu fui para a sala de parto com o médico falando que a bebê não iria sobreviver, falou para mim e para o meu marido que eu também poderia não sobreviver.Se fosse assim outros bebês também tinham sobrevivido, com mais peso até do que o dela e não sobreviveram. Ela ficou calada, sem resposta...
\end{abstract}

Através da utilização peculiar do enquadre desta pesquisa, Wanda pôde transitar entre dois níveis que, segundo Guattari (2005), no plano da micropolítica ${ }^{6}$ se opõem: o do grupo sujeitado, que sofre hierarquização por ocasião de seu acomodamento aos outros grupos e que tende a ser manipulado por todas as determinaçôes externas e dominado por sua própria lei interna. E o grupo sujeito, ou seja, aquele que enuncia algo que possui por vocação gerir, na medida do possível, sua relação com as determinações externas e com sua própria lei interna. A partir daí, podemos compreender que foi estabelecida uma comunicação entre dois pólos de referência, até então opostos: o de uma subjetividade com vocação a tomar a palavra possibilitada por seu consentimento em fazer parte de um projeto de pesquisa e uma subjetividade alienada, que "perde de vista" a alteridade característica do ingresso na instituição como usuária da assistência.

Assim, a subjetividade circularia por entre modos de produção distintos ${ }^{7}$ não estando centrada em agentes individuais ou grupais, mas na conexão entre ambos e, quando assumida e vivida por indivíduos em suas existências particulares, oscila entre a alienação, submissão à subjetividade tal como ela é recebida oriunda de conjuntos sociais, e uma relação de expressão e de criação, uma reapropriação individual de seus componentes que se produz por meio do processo de personalização. Desta forma, Wanda oscilou entre uma relação de alienação e opressão, na qual se submeteu ao modelo de comunicação que lhe informou sobre a morte, e uma relação de expressão e criação, na qual se reapropriou da experiência subjetiva ligada a esta informação de forma singular. Este trânsito entre a alienação e a singularização produziu na prática relacional compreendida pela pesquisa o 
efeito da transversalidade, ou seja, o da busca de uma comunicação que se realiza entre diferentes níveis hierárquicos e, sobretudo em diferentes sentidos, por meio da qual ela escapa da mera sujeição.

Referindo-se ao interior do ambiente intensivo, Wanda falou: "Ontem eu vi o médico com quem eu estive na época da internação quando eu tava grávida..., ele me preparando para o óbito dela e para o meu também. Então eu quase falei com ele, ah, me deu uma vontade de falar assim: 'Viu doutor como a medicina precisa evoluir'. Ah, me deu uma vontade de falar isso, então eu fiquei bem olhando para ele, porque achei que não tinha necessidade dele falar tudo aquilo que ele falou. Telefonou para o meu marido, falou que ele precisava vir viajando de tão longe, então até ele estava se preparando para dois enterros".

Wanda, na relação com a equipe médica, valorizou de forma negativa as comunicações sobre o riscos inerentes à situação que atravessava, sentindo-se freqüentemente mais perseguida do que estabelecendo uma relação de confiança. Ao relatar seu sentimento de solidão nesses momentos, quando distante da família, da assistência médica de sua cidade, e mesmo que em um hospital mais sofisticado, estava diante de uma situação da qual não podia se libertar e que lhe foi apresentada como sendo provavelmente insuperável. Encontrou-se diante do limite, comum a todos nós, que é o da morte.

Elias (2001), em seu belíssimo trabalho sobre a solidão dos que se encontram diante deste limite, nos diz que dentre as criaturas que morrem na Terra, a morte cria problemas somente para os seres humanos, pelo fato de possuírem conhecimento sobre a mesma. Desta forma, não seria a própria morte que desperta temor e terror, mas sua imagem antecipada. $\mathrm{O}$ terror e o temor seriam despertados somente pela imagem da morte na consciência dos vivos. Em sua forma social seria específicamente moldada, de acordo com o estágio alcançado pelo desenvolvimento da humanidade e da civilização. O que Wanda nos traz através destas experiências autoriza uma reflexão sobre a relação entre ética e comunicação médico paciente.

A informação sobre o risco, quando referida a uma normatização da conduta profissional, ou seja, na relação do profissional de saúde com um código, é prevista como uma conduta desejável. Assim, a aproximação dessa relação através da ótica restrita ao exercício de uma profissão nos apresenta a ética como um conjunto de normas que regulamentam e normatizam o comportamento, com a finalidade de orientar as relações profissionais entre os pares, destes com seus clientes, com sua 
equipe de trabalho e com as instituições a que servem. Pelo prisma da deontologia, a ética médica se torna específica e objetiva, através de códigos elaborados por associações que orientam respostas para questões específicas do exercício profissional.

A comunicação nessa história de vida, sobre o possível óbito de mãe e filha durante o procedimento cirúrgico, é umas das situaçôes do exercício do profissional que podemos supor como prevista no Código Brasileiro de Ética Médica homologado pelo Conselho Federal de Medicina. Neste, no capítulo 5, que trata da relação com pacientes e familiares, traz em seu artigo 59 que é vedado ao médico deixar de informar ao paciente o diagnóstico, o prognóstico, os riscos e objetivos do tratamento, salvo quando a comunicação direta ao mesmo possa provocar-lhe dano, devendo, neste caso, a comunicação ser feita a seu responsável legal. No entanto, tal perspectiva, a da normatização proposta por um código profissional, pode, como no caso de Wanda, pender a uma verticalização da relação quando não leva em conta a tensão produzida pelo encontro das diferenças de perspectivas (FREIDSON, 1970) - ou seja, o encontro entre a autoridade profissional do médico e a dependência dos mesmos pelo paciente.

A tensão desse encontro nos remete à necessidade de compreender sua assimetria quando, por exemplo, podemos supor que em uma maternidade cuja assistência é especializada para o atendimento de gestantes de risco, o profissional de saúde possívelmente estivesse diante de uma situação de rotina e Wanda diante de uma situação-limite. A ética que se refere a situações-limite pode nos levar ao encontro de outro tensionamento existente na relação entre o profissional e seu código normativo e o profissional com o paciente.

Quando, anteriormente, se fez referência à implicação da pesquisadora, desejouse demonstrar a forma como esta foi utilizada a partir dos recursos oferecidos pelo surgimento do analisador em relação aos processos da humanização de assistência. Como é o analisador aquele que conduz a análise, compreendeu-se que a interpretação da conjuntura institucional que foi realizada por Wanda permitiu que este trabalho de pesquisa apontasse para o conteúdo de sua encomenda dirigida à instituição. Desta forma, Wanda demandava ${ }^{8}$ outra modalidade de atuação ética, uma atuação profissional não-normatizada, ou seja, a que se poderia existir no encontro entre singularidades em que a identificação com o sofrimento do outro modelaria a forma e o tempo em que informaçōes sobre o risco seriam transmitidas. Refiro-me, portanto, à demanda por uma ética da diferença e da singularidade 
que aqui está ligada à posição do profissional diante da morte e do morrer na relação com aquele confrontado situacionalmente com esse limite. Teriam recursos os profissionais de saúde para avaliar o impacto que sofrem diante de tais situações e, principalmente para, na captura da subjetividade, utilizá-la de forma personalizada na relação com o paciente?

Quando nos aproximamos desta questão, a da subjetividade que atravessa a prática do profissional de saúde, podemos abordá-la a partir do pressuposto de que sua produção se realiza tanto por instituições responsáveis pela formação médica como por aquelas em que sua prática é organizada como profissão. E, se anteriormente, através do conceito de analisador, procurou-se demonstrar os modos de relaçôes sociais já instituídos na relação médico-paciente a partir de um movimento individual, a fala de Wanda se dirigiu ao coletivo questionando o sentido da ética instituída.

A partir do já instituído e do coletivo, podemos seguir para uma compreensão do individual, ou seja, da forma como o profissional de saúde introjeta o fluxo da subjetividade produzida pelas instituições que ensinam e organizam sua prática profissional. Continuando a seguir a proposta de Guattari (2005), de que a subjetividade estaria em circulação por entre conjuntos sociais, sendo assumida e vivida por indivíduos em suas existências particulares, o conceito de território," se ligado ao ensino e à organização profissional, aproxima-se da forma como a antropologia apresenta os aspectos subjetivos ligados ao exercício do profissional de saúde.

Good (1994) nos remete a uma alternativa em relação à arqueologia da estrutura epistemológica do discurso médico, como proposta por Foucault, para a compreensão dos processos que envolvem a formação da identidade do estudante de medicina. Segundo o autor, não se pode desconsiderar o papel do sujeito da consciência na construção da prática médica, uma vez que a prática não pode ser analisada na ausência de seus praticantes ou reduzida à análise da tecnologia do poder em detrimento da intencionalidade dos sujeitos. A transmissão do conhecimento médico não se dá de forma simplesmente cognitiva, mas por meio de "um mergulho profundo" em um mundo de experiências distintas do mundo da realidade cotidiana.

O corpo e a patologia são formulados a partir de uma realidade específica, que inclui formas de percepção especializadas, adquiridas através de intenso treinamento da visão, da escrita e da fala. A visão da dissecação auxilia a pensar "anatomicamente", 
possuindo importância similar para os estudos de histologia e patologia e também para a qualidade da interpretação das imagens tecnológicas produzidas por aparelhos de exames físicos. Através da escrita e da fala, aprende-se a conversar "da maneira certa" ou seja, a interpretar descrições fenomenológicas do comportamento em formas de funcionamento fisiológico e em processos patofisiológicos através dos quais se reafirma que a doença é exclusivamente biológica (ainda quando se reconheçam as questões psicossociais, elas não fazem parte do objeto da prática médica).

A relação entre fisiologia e patologia produz as histórias clínicas através das quais se "assenta" uma consciência ligada à importância da performance que se dá através da introjeção da responsabilidade pela vida de outrem, a responsabilidade médica. Neste sentido, a questão do diagnóstico e a indicação do tratamento para uma doença são consequências do ingresso em um processo de formação profissional que se realiza através da submissão à hierarquia no interior de instituições (observação, disciplina, controle e ensino), onde ocorrem supervisōes e freqüentes avaliações. Assim, a formação médica é parte de uma hierarquia que autoriza o ensino, a aprendizagem de procedimentos, a avaliação, a punição e a regulamentação de experiências que objetivam maximizar o controle e a gerência dos erros e a competência daqueles que as realizam. Através da educação, modelos de prática são definidos para limitar arbitrariedades e riscos, ao mesmo tempo em que constroem os objetos, reproduzindo relaçôes de poder que envolvem o processo de aprendizagem.

A profissão médica possui peculiaridades distintas, sem precedentes em relação à disciplina, duração e rigidez contidos em sua aprendizagem, o que caracteriza a idéia da "criação" de uma nova pessoa que no curso de um treinamento intensivo absorve o conhecimento que necessita para estar seguro, ter a ansiedade reduzida e alcançar a capacidade de enfrentamento da "incerteza básica" característica da prática clínica. No entanto, Friedson (1970) demonstra que não é a educação a mais importante influência em relação à responsabilidade médica, mas sim a organização do setting no qual o profissional trabalha após sua formação. Neste sentido, a avaliação e o controle sobre a responsabilidade médica variam conforme os modelos de práticas organizadas.

No caso de Wanda, está em jogo uma instituição hospitalar de referência para a rede pública da assistência à gravidez de risco e ao parto prematuro, bem como um pólo de formação médica em nível de residência e pós-graduação. Aproxima-se, portanto, do que Friedson (1970) descreve como sendo aquelas em que ao mesmo 
tempo os profissionais detêm o monopólio sobre suas práticas, e a fonte do poder e da autoridade advém do estado que determina, através de suas políticas, um tipo de assistência garantido por lei. Tais instituições possuem uma forma distinta de burocracia, uma burocracia profissional, onde a hierarquia da prática existe em separado da hierarquia da administração. Em tais entidades, existe uma situação de interdependência caracterizada pela observação e influência dos profissionais uns sobre os outros em relação à responsabilidade médica, o que parece ser determinante para a autonomia científica e tecnológica que avaliza suas práticas.

Assim, apesar da vigilância administrativa e da dependência do Estado, a prática médica tende a "administrar cabeças", responsabilizando-se por modelos de técnicas, equipamentos, procedimentos e performances. Se os profissionais não estão inteiramente livres do controle de seu tempo e condição de trabalho, têm autonomia em relação ao conteúdo de sua profissão e especialidade. Neste sentido, será a forma de organização institucional considerada, enquanto unidade, em detrimento da prática individual, a fonte do poder da autoridade que somada à competência técnica implicam homogenização da avaliação dos serviços.

Se, dentre os modelos descritos acima, referentes a formação e organização da prática profissional, podemos supor a produção e a circulação de determinadas formas de subjetividade que seriam introjetadas individualmente pelo profissional de saúde, quais seriam as possibilidades de existirem dificuldades para sua personalização? Levando-se em conta o exemplo de Wanda, podemos nos aproximar do que nos é apresentado por Correa (1983) sobre a questão da iatrogenia ${ }^{10}$ médica, quando abordada pelo viés da relação com o paciente. $\mathrm{O}$ autor utiliza a aplicação do conceito psicanalítico de identificação ${ }^{11}$ para abordar a dissemetria existente na situação em que o paciente habitualmente procura no médico um controle absoluto de sua doença, "um controle onipotente da patologia”, por estar preso à ameaça de aniquilamento. Procura, assim, alguém que o escute, ajude a lidar com o incontrolável, o repentino e com o estranho que é a doença. $\mathrm{O}$ médico, por sua vez, possui uma visão na qual sua prática possui uma representação simbólica culturalmente referida ao sofrimento, às formas de transformação e transcendência do sofrimento e ao encontro da redenção através da cura. Para Corrêa (1983), no tensionamento de tais expectativas existiriam quatro possibilidades, relativas à aquisição, pelo médico, de uma identidade momentânea vinculada à interação com o paciente. 
Na primeira se identificaria com a instituição, que reconhece como opressora, vivenciando-a internamente como inimiga mas, paradoxalmente, se identificando com ela. Sua ação com seu paciente seria de dominação absoluta, maltratando-o, agredindo-o e percebendo-o como um obstáculo a seu trabalho e não como fonte de inspiração para o mesmo. Na segunda, o médico se identificaria com aspectos parciais da personalidade do paciente, predominantemente agressivos e sádicos, agindo não segundo critérios de cura e alívio, mas dirigindo-se a esses aspectos parciais de sua personalidade por estar intimamente identificado com eles. Amostra desta situação é a do paciente masoquista que seduz o médico para a indicação de procedimentos cruentos, muitas vezes desnecessários, se avaliados com profundidade. A terceira possibilidade é a da identificação do médico com objetos reais da vida do paciente, como por exemplo, com algum membro da família. $\mathrm{Na}$ quarta possibilidade, o médico se identificaria diretamente com os aspectos do paciente, geralmente dolorosos, e ao perceber isso, se distanciaria, defendendo-se da percepção da identificação.

Acredito que entre essas formas de identificação com o paciente circulem as dificuldades de se personalizar, através do processo de introjeção da subjetividade produzida pela formação e organização da prática médica, situações como a da informação sobre a morte e o morrer, conforme apresentado pela interpretação realizada pelo analisador. Segundo Kübler-Ross (1979), o momento de contar, ou seja, o da confirmação do diagnóstico, é uma informação que prontamente deve ser dada ao paciente, mas incentivando-lhe esperança e informando-o sobre todas as possibilidades de tratamento. Desta forma, o paciente saberia que possui uma grave enfermidade, mas também o que é humanamente possível de ser feito o será para ajudá-lo.

A autora, porém, orienta no sentido de que nenhum paciente deve ser informado de que está morrendo, pois ninguém deve forçar pacientes a encarar sua morte sem que estejam preparados para tanto, ou privá-los de ter esperança. Os pacientes, bem como suas famílias, devem ser informados sobre a gravidade da situação, mas não se aborda o problema da morte; espera-se que este seja suscitado. A "síndrome de Lázaro", que metaforicamente podemos utilizar em relação à sobrevivência de Wanda e sua filha, contradiz a informação do diagnóstico médico, demonstrando quão falível foi o modelo de comunicação utilizado, na medida em que o ressentimento reforçou a distância e a dissemetria na relação com os profissionais 
de saúde, não se estabelecendo uma situação de júbilo entre médico e paciente, que quando companheiros realizam nestas situações uma travessia que envolve riscos mas também esperanças.

Encontro Wanda com o rosto inchado de tanto chorar e essa foi nossa última conversa no interior da UTI: "O pessoal daqui está falando que não é para eu ficar neurótica, eu não estou neurótica. Vou com ela para casa hoje. Você soube o que aconteceu antes de ontem? Ela foi operada ${ }^{12}$ e eu disse: pois é doutor. ela veio tão bem até aqui, o senhor sabe ela nasceu com 510 grs., não é agora que vai dar alguma coisa errada, né?. Deram a anestesia geral então ela voltou entubada e tudo, depois desentubaram e aí passou um pouquinho, ela ficou toda roxa, mas roxa mesmo, quase preta. Foi uma correria de um lado para o outro. Aí elas me explicaram que foi como se ela tivesse tido uma pequena parada. Depois fizeram a ultra-som e viram que ela não ficou com nenhum coágulo com nada. Eu sei que não vai acontecer nada, que já passou mas foi um susto. E também agora parece que nas outras crianças não vão mais usar anestesia geral, só local para evitar isso que aconteceu com ela. E também nós somos meio cobaias, eles fazem o que querem com a gente. Lembra que eu te falei de uma médica que estava no dia em que ela nasceu, que disse que era para eu me preparar porque poderia ser que ela não sobrevivesse? Pois é ela veio falar comigo, veio falar e apresentar minha filha para o marido dela que trabalha aqui. Aí me fez um monte de perguntas sobre a pressão na gravidez, se eu tomei alguma remédio, alguma coisa, aí eu lembrei para ela o que ela falou.Ela não precisava ter falado, até porque como é que a gente entra aqui com isso na cabeça? É difícil!”.

\section{Conclusão}

Ao considerarmos a investigação sobre o humor materno em mães de bebês prematuros após a alta hospitalar, temos, através do que foi exposto anteriormente, que o processo de humanização da assistência em unidade de tratamento intensivo não possibilita uma comunicação médico-paciente capaz de levar em conta a especificidade da experiência singular desta mãe. Em relação especificamente á saúde reprodutiva em sua interface com a gravidez de risco e parto prematuro, a implementação de mecanismos de escuta por equipes multidisciplinares se faz necessária para a compreensão do significado atribuído pelas mães ao acompanhamento da internação de seus filhos.

A urgência de uma atitude de compreensão solidária muitas vezes é dificultada (WAINER; KHUZWAYO, 1993) pela qualidade de comunicação estabelecida 
entre a equipe técnica e parentes de pacienes que apresentam alto risco, como a situação de hipertensão de Wanda e a do extremo baixo-peso de sua filha ao nascer. Atitudes negativas dos profissionais em relação aos familiares podem então se relacionar com a gravidade da situação clínica, como foi demonstrado na forma como as informações sobre o risco eram transmitidas para Wanda e seu esposo.

O suporte de um comitê de bioética que possua ligações com agências externas à instituição e que, ao mesmo tempo, participe localmente de decisões críticas relacionadas à assistência em unidade de tratamento itensivo no que toca à circulação das informaçôes sobre o risco de vida é uma experiência que já possui resultados em países como Reino Unido (CAMPBELL; LLOYD; DUFFY, 1998), Japão (NISHIDA, 1987) e Holanda (SAUER, 1992). Mesmo que não possamos comparar a situação das equipes técnica e parentes de bebês internados em unidade de tratamento intensivo de países desenvolvidos com as de países em desenvolvimento, em função das diferenças socioeconômicas profundamente acentuadas, muito podemos aprender. É preciso que a política de humanização da assistência em seu eixo de gestão indique o acompanhamento e avaliação sistemáticos das ações realizadas nessas unidades pelos comitês de bioéticas destas mesmas instituições.

Desta forma, este trabalho se aproxima de uma determinada linha de conhecimento da boética contemporânea representada por uma assimilação da perspectiva crítica quanto à participação de seres humanos em pesquisas científicas (DINIZ; GUILHEM, 2000, DINIZ; CORREA, 2001). Esta posição propõe uma bioética que teórica e tecnicamente se posicione em oposição aos pressupostos clássicos do principialismo, propondo que se organize uma atuação em que seja possível espelhar a estrutura de poder dominante. Orienta-se pelo pressuposto de que não é possível falar em princípios absolutos mediadores dos conflitos morais, mas de mecanismos de reparação social da vulnerabilidade moral.

Dos princípios éticos universais, passaríamos para a defesa dos princípios compensatórios da vulnerabilidade social. Assim, a inserção do analisador natural, produto da relação entre pesquisador e sujeito da pesquisa, inseriu a questão da diferença como um valor moral que foi preservado na construção do conhecimento sobre a questão do humor materno em mães de bebês prematuros após a alta hospitalar. A partir da inclusão, na forma de conhecimento, do que historicamente é desconsiderado em estudos éticos, a experiência da alteridade, este trabalho se propõe a contribuir para reflexões sobre a busca por mudanças nas relações sociais 
que se caracterizam pela dominação e subordinação que dificultam a comunicação em situações de assistência à saúde.

\section{Referências}

ARISTÓTELES. Ética a Nicômaco. São Paulo: Nova Cultural, 1991.281p.

CAMPBELL, A. G. M.; LLOYD, D. J.; DUFFTY, P. Treatment dilemmas in neonatal care: who should survive and who should decide? Annals of the New York Academy of Sciences New York: Blackwell Publishing, 1998. 292p.

CHAUÍ, M. O que éIdeologia. São Paulo: Brasiliense, 2002 (Coleção Primeiros Passos).

CORREA, O. S. F. Iatrogenia e identificação. Cadernos de Saúde, v. 1, n. 1, p. 18-19, 1983.

DINIZ, D.; CORRÊA M. V. D. Declaração de Helsinki: vulnerabilidade e pesquisa científica. Cadernos de Saúde Pública, v. 17, n. 3, p. 679-688, 2001.

DINIZ, D.; GUILHEM, D. Bioética feminista: o resgate político do conceito de vulnerabilidade. Bioética, v. 7, p. 181-187, 2000.

ELIAS, N. A solidão dos moribundos. Rio de Janeiro: Jorge Zahar, 2001. 107p.

FREIDSON, E. Professional dominance: the social structure of medical care. New York: Atherton Press, 1970. 242p.

GOOD, B. J. Medicine, rationality, and experience: an anthropological perspective. New York: Cambridge University Press, 1994. 242p.

GUATTARI, F. Revolução molecular: pulsações políticas do desejo. São Paulo: Brasiliense, 1987.230p. GUATTARI, F.; ROLNIK S. Micropolíticas: cartografias do desejo. Petrópolis: Vozes; 2005. 326p. JORGE, M. A. S. Engenho dentro de casa: sobre a construção de um serviço de atenção diária em saúde mental. 1997. Dissertação (Mestrado em Saúde Pública) - Fundação Oswaldo Cruz, Escola Nacional de Saúde Pública, Rio de Janeiro, 1997.

KÜBLER-ROSS, E. Perguntas sobre a morte e o morrer. São Paulo: Martins Fontes, 1979. 176p.

MINAYO, M. C. S. Contribuições da antropologia para pensar a saúde. In: CAMPOS, G. W. S. et al. (Org.). Tratado de Saúde Coletiva. São Paulo: Hucitec, 2006. p. 201-230.

. O desafio do conhecimento. Pesquisa qualitativa em saúde. São Paulo: Hucitec, 1992. 269p.

NISHIDA, H. Future ethical issues in neonatology: a Japanese perspective. Seminars in Perinatology, v. 3, n. 11, p. 274-278, jul. 1987.

SAUER, P. J. J. Ethical decisions in neonatal intensive care units: The Dutch experience. Pediatrics, v. 89, n. 4, p. 729-732, Apr. 1992. 
VIDAL, M. Dor e superação de mães e bebês prematuros-trajetórias da UTI para o convívio familiar. 2006. 209p. Tese (Doutorado em Saúde da Mulher) - Fundação Oswaldo Cruz, Escola Nacional de Saúde Pública, Instituto Fernandes Figueira, Rio de Janeiro, 2006.

WAINER, S.; KHUZWAYO, H. Attitudes of mothers, doctors and nurses toward neonatal intensive care in a developing society. Pediatrics, v. 6, n. 91, p. 1.171-1.175, Jun. 1993.

\section{Notas}

${ }^{1}$ A socioanálise e a análise institucional são abordagens desenvolvidas a partir dos anos 40-50 que utilizam conceitos e instrumentos relativos à dinâmica das instituições. Desenvolvem conceitos e instrumentos relativos a intervenções nas instituições, e têm origem no institucionalismo francês. Suas influências provêm, por um lado, da tradição dialética contida na obra de René Lourau e George Lapassade, e por outro, na "esquizoanálise" inspirada na filosofia da diferença de Félix Guattari e George Deleuze.

${ }^{2}$ Foram movimentos que criticavam a estrutura asilar, priorizando a comunidade como lugar de atuação da psiquiatria. Nesse grupo se incluem a Psiquiatria Preventiva e a Psiquiatria de Setor. Instauravam rupturas na constituição do saber médico sobre a loucura. Estão presentes nesse grupo o movimento da Antipsiquiatria e a Psiquiatria Democrática Italiana.

${ }^{3}$ Assembléias e grupos operativos, por exemplo.

${ }^{4}$ Para a socioanálise, encomenda ou encargo é o que aparece através da fala, sendo anterior a sua interpretação e se referindo a uma demanda produzida de forma a incidir sobre processos de produção de singularidade opostos aos de alienação.

${ }^{5}$ Nome fictício.

${ }^{6} \mathrm{O}$ autor situa a problemática da micropolítica não no nível da representação, mas no da produção de subjetividade que se refere aos modos de expressão que passam não só pela linguagem, mas também por níveis semióticos heterogêneos incidindo nos pontos de singularidade, em processos de singularização, que são as próprias raízes produtoras de subjetividade em sua pluralidade. Como micropolítica do desejo, propõe um conjunto teórico provisório que permite abordar tanto os problemas individuais como os sociais, a partir do pressuposto de que o acúmulo de lutas parciais desencadearia lutas coletivas. O objeto social é colocado em condiçōes, através do analisador, de tomar a palavra sem ter que recorrer a instâncias representativas para exprimir-se.

${ }^{7}$ A produção de subjetividade constituiria matéria-prima de toda e qualquer produção, não existindo um contraponto, por exemplo, entre as relações de produção econômica e relaçôes de produção subjetiva.

${ }^{8}$ Para a Socioanálise, a demanda só surge a partir da intervenção, que neste caso está caracterizada pela produção do conhecimento através da realização da pesquisa. Está ligada à existência de classes sociais e sua luta, sendo freqüentemente contraditória em relação à encomenda. 
${ }^{9}$ Apropriação, um processo de subjetivação fechado em si mesmo (GUATTARI, 2005) e que produz representações que se infiltram pragmaticamente por toda uma série de comportamentos, investimentos, tempos, espaços (sociais, culturais, estéticos) e de saberes instituídos, nos auxilia na compreensão de determinados modos de produção de subjetividade.

${ }^{10}$ Doença ou dano que se origina da prática médica ou medicinal, que surge em conseqüência da intervenção médica ou medicamentosa.

${ }^{11}$ Processo central, para a teoria psicanalítica, pelo qual o sujeito psíquico se constitui e se transforma, sendo expressão primária de ligação afetiva com outra pessoa. O sujeito assimila ou se apropria em momentos-chave de sua evolução, dos aspectos, atributos ou traços dos seres humanos que o cercam. Existiriam três tipos de identificação: a que se refere a uma etapa do desenvolvimento emocional muito primitiva, pré-edípica; a do estado oral, de incorporação, em que não se distingue o investimento sexual do objeto, a regressiva, presente no sintoma histérico, e aquela em que se efetua na ausência de investimento sexual, tratando-se da "vontade, da capacidade, de se colocar na situação do outro ou dos outros". Esta última se refere à formação das comunidades afetivas, que ligariam entre si os membros de uma coletividade.

${ }^{12}$ Cirurgia de hérnia umbilical. 
On a certain use of model in health qualitative research: the natural analyzer issue This article aims to demonstrate the inclusion, in the limits of the methodological model of health qualitative research, of a natural analyzer arising from the dynamics of the relation between researcher and research subject. The inquiry on the maternal mood among mothers of premature babies after hospital discharge, object of doctorate research in Woman's Health (Fiocruz-Institute Fernandes Figueira), had an interface with the emotional reactions lived within the intensive care environment. The analysis and interpretation of the material concerning this period helped repairing the condition of moral vulnerability of group that is often excluded of the awareness about the processes of humanized health care, of mothers in joint lodging during their children's internment, thus contributing for reflections on the ethics in research with human beings.

> Key words: ethics, natural analyzer, qualitative research. 